\title{
Does Patient Sex Affect the Rate of Mortality and Complications After Spine Surgery? A Systematic Review
}

\author{
Andrew J. Schoenfeld MD, MSc, Elyse N. Reamer BS, \\ Emily I. Wynkoop BS, Hwajung Choi PhD, \\ Christopher M. Bono MD
}

Published online: 18 December 2014

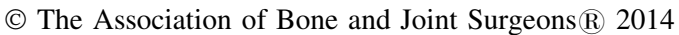

\begin{abstract}
Background Available studies disagree regarding the influence of patient sex on mortality and complications after spine surgery. We sought to conduct a systematic review and pool the results of existing research to better understand this issue.

Questions/purposes We performed a systematic review to address two questions: (1) Does sex (male versus female) influence mortality after spine surgery? (2) Does sex impact the development of postoperative complications after spine surgery?
\end{abstract}

\footnotetext{
One of the authors (AJS) is a Robert Wood Johnson Foundation Clinical Scholar. The Robert Wood Johnson Foundation and the Department of Veterans Affairs were not directly involved in study design, data acquisition and interpretation, or manuscript preparation or review. Any opinions expressed herein do not necessarily reflect the opinions of the Robert Wood Johnson Foundation or the Department of Veterans Affairs.

All ICMJE Conflict of Interest Forms for authors and Clinical Orthopaedics and Related Research ${ }^{\circledR}$ editors and board members are on file with the publication and can be viewed on request. This work was performed at the Robert Wood Johnson Clinical Scholars Program, University of Michigan, Ann Arbor, MI, USA.
}

Electronic supplementary material The online version of this article (doi:10.1007/s11999-014-4102-z) contains supplementary material, which is available to authorized users.

A. J. Schoenfeld $(\square)$

Department of Orthopaedic Surgery, University of Michigan, Ann Arbor Veterans Administration Hospital, 2800 Plymouth Road, Building 10, RM G016, Ann Arbor, MI 48109, USA

e-mail: ajschoen@neomed.edu

E. N. Reamer, H. Choi

Robert Wood Johnson Clinical Scholars Program, University

of Michigan, Ann Arbor, MI, USA
Methods This systematic review was performed through a query of PubMed using a structured search algorithm. Additional queries of Embase, SCOPUS, Web of Science, and the tables of contents of orthopaedic and neurosurgical journals were also conducted using search terms such as "sex factors", "male or female", "risk factors", and "spine surgery". Selected papers were independently abstracted by three of the authors (AJS, ENR, EIW) and pooling was performed. Our literature search returned 720 studies, of which 99 underwent full review. Of these, 50 were selected for final abstraction. The Cochrane Q test was used to assess study heterogeneity; significant study heterogeneity was present and so a random-effects model was used. A Harbord test was used to evaluate for the presence of publication bias; this analysis found no statistically significant evidence of publication bias.

Results Males were at increased odds of mortality after spine surgery (odds ratio [OR], 1.63; 95\% confidence interval $[\mathrm{CI}], 1.35-1.97 ; \mathrm{p}<0.001)$. No differences between the sexes were identified for the odds of complications (OR, 1.04; 95\% CI, 0.95-1.13; $\mathrm{p}=0.42$ ).

Conclusions Our results determined that males were at elevated odds of mortality but not of complications after spine surgery. These results should be used to inform preoperative discussion and decision-making at the time of surgical consent. Future work should be directed at determining the underlying factors responsible for increased

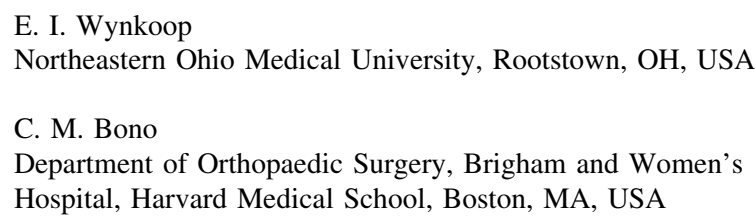


mortality among males and prospective studies specifically designed to evaluate sex-based differences in outcomes after spine surgery.

Level of Evidence Level III, therapeutic study.

\section{Introduction}

Sex-based differences in the risk of postoperative morbidity between males and females are known to exist within a broad number of disciplines, including cardiothoracic and trauma surgery $[56,58]$. By sex, we mean the biological character of male and female patients as opposed to gender, which reflects societal roles and expectations. Within the field of orthopaedic surgery, a patient's sex is thought to influence outcomes after total joint arthroplasty, particularly with respect to total knee arthroplasty [32]. The impact of male or female sex on the risk of mortality and complications after spine surgery is less well defined.

There are a number of hypothetical reasons that males and females might have differing mortality and complication profiles after spinal surgery. Variation in anthropomorphic parameters, body mass indices, and comorbidity profiles may contribute to disparities in complication and mortality risks between the sexes after spine surgery. Distinct differences in tobacco and alcohol abuse as well as risk-taking behavior might also elevate the odds of postoperative death or the development of specific complications such as surgical site infection (SSI). Sexbased differences with respect to the incidence of specific spinal disorders have previously been described, including lumbar degenerative disc disease [49], lumbar radiculopathy [48], and cauda equina syndrome [45]. Furthermore, previous work [55] has identified that males are more likely than females to receive recommendations for spine surgery despite similar underlying disorders [55]. Most prior research has failed to address whether males or females may be at increased risk of morbidity or mortality after spine surgery. Furthermore, many studies that have considered this topic have come to contradictory conclusions. For example, when considering the risk of complications after spine surgery, Schoenfeld et al. [50] and Shen et al. [52] concluded that females were at increased risk, whereas Cahill and colleagues [3] claimed that males were at elevated risk of postoperative morbidity. Many of these studies are limited by small samples and statistical pooling could allow for sufficient power to reach more precise conclusions.

In this context, we sought to perform a systematic review of the literature and meta-analysis to address two questions: (1) Does sex (male versus female) influence the odds of mortality after spine surgery? (2) Does sex impact the odds of postoperative complications after spine surgery?

\section{Search Strategy and Criteria}

The initial literature search was performed by three independent investigators (AJS, ENR, EIW) using a structured algorithm (Appendix 1 [Supplemental materials are available with the online version of $\mathrm{CORR}^{\circledR}$.]) that queried the published catalog in PubMed from 1966 to May 29, 2014. An additional search was performed in Embase using an Emtree algorithm comparable to the PubMed approach; supplemental queries were conducted in Web of Science and SCOPUS (AJS, ENR, EIW). A manual search of article titles in the reference lists of studies found to meet inclusion criteria was subsequently conducted to capture additionally relevant research that had not been identified in the first rounds of the systematic review. Finally, the catalogued tables of contents of Clinical Orthopaedics and Related Research ${ }^{\circledR}$, The Spine Journal, Spine, Journal of Spinal Disorders and Techniques, Journal of Neurosurgery, Journal of Neurosurgery: Spine, European Spine Journal, and Journal of Bone and Joint Surgery (American) were searched electronically using key words to ensure that the initial search was exhaustive.

The titles and abstracts of studies identified by each query were evaluated and full-text articles were reviewed if the work appeared to meet inclusion criteria. To be included in the final review, investigations had to be published in the peer-reviewed literature and evaluate biologic sex as a risk factor for mortality or postoperative complications in adult patients (aged 18 years and older) undergoing a surgical intervention involving the cervical, thoracic, or lumbar spine. Results of eligible studies had to detail the number of patients sustaining the outcomes of interest by sex and/or evaluate their findings through statistical testing with significance reported by $\mathrm{p}$ value and/or effect size with 95\% confidence intervals (CIs). Case reports, systematic reviews, investigations that included pediatric cases or involved spinal trauma, unpublished studies, and those in which no surgery was performed were excluded as were those with patient sample sizes less than 100 and those that involved a single sex cohort (Level IV evidence).

Determinations regarding study inclusion were made independently by three investigators (AJS, ENR, EIW) with disagreements resolved by mutual consensus. Studies included in the final review were abstracted to identify authors, year of publication, journal of publication, study quality, number of patients included in the study, number of males and females who died or sustained a complication, and statistical results regarding the influence of sex on the 
risk of mortality and/or complications. Randomized prospective trials were considered Level I evidence, prospective cohort studies were considered Level II, and retrospective case-control analyses were considered Level III. Irrespective of the level of evidence applied at the time of publication, studies that performed post hoc testing for heterogeneity of treatment effects were considered Level III quality for the purposes of our review. The literature search and manner of reporting results met the criteria advocated by the Preferred Reporting of Items for Systematic Reviews and Meta-analyses (PRISMA) statement [34].

Investigations that detailed the total number of patients and mortality and complication rates by sex were considered suitable for pooling. Study heterogeneity was assessed using the Cochran $\mathrm{Q}$ test with $\mathrm{p}$ value for significance set at 0.10 and the $\mathrm{I}^{2}$ statistic. Summary measures of effect size were reported using a pooled odds ratio (OR) with $95 \% \mathrm{CI}$. Publication bias was assessed with Harbord's modified bias test for small-study effects [54].

The literature search identified 720 published studies (293 from PubMed, 99 in Embase, 229 from SCOPUS, 65 from Web of Science, and 34 from reference lists). No additional articles not otherwise identified in the literature search were obtained from the table of contents query of selected journals. After assessment of the title and abstract, or as duplicate citations, 621 studies were excluded, leaving 99 publications for full-text review (Fig. 1). After fulltext review, an additional 49 publications were excluded. The majority of these $(n=27)$ were excluded because they did not report complications or mortality by patient sex. A further 14 were excluded because they included pediatric patients. Six studies were excluded as a result of sample size less than 100 , one study was excluded as a result of its being a systematic review, and one was excluded because no spine surgery was performed. Ultimately, 50 studies $[1-31,33,35-44,46,47,50-53,57,59]$ that met all inclusion criteria necessary to evaluate the influence of sex on mortality (Appendix 2 [Supplemental materials are available with the online version of $\mathrm{CORR}^{\circledR}$.]) and complications (Appendix 3) after spine surgery were included. Five studies addressed mortality, five assessed mortality and one or more complications, and 40 dealt exclusively with one or more complications. Complications considered in the individual studies included venous thromboembolic disease, SSI, dysphagia after anterior cervical procedures, perioperative visual loss, neurological deficits, and reoperation (Appendix 3). The plurality of cohorts $(n=17$ [27\%]) evaluated nonspecific postsurgical complications. Five studies considered dysphagia after anterior cervical spine procedures, eight reported on SSI, five documented need for reoperation, and five evaluated the development of venous thromboembolic disease. No prospective trials on sex-related differences in spine surgery were identified and

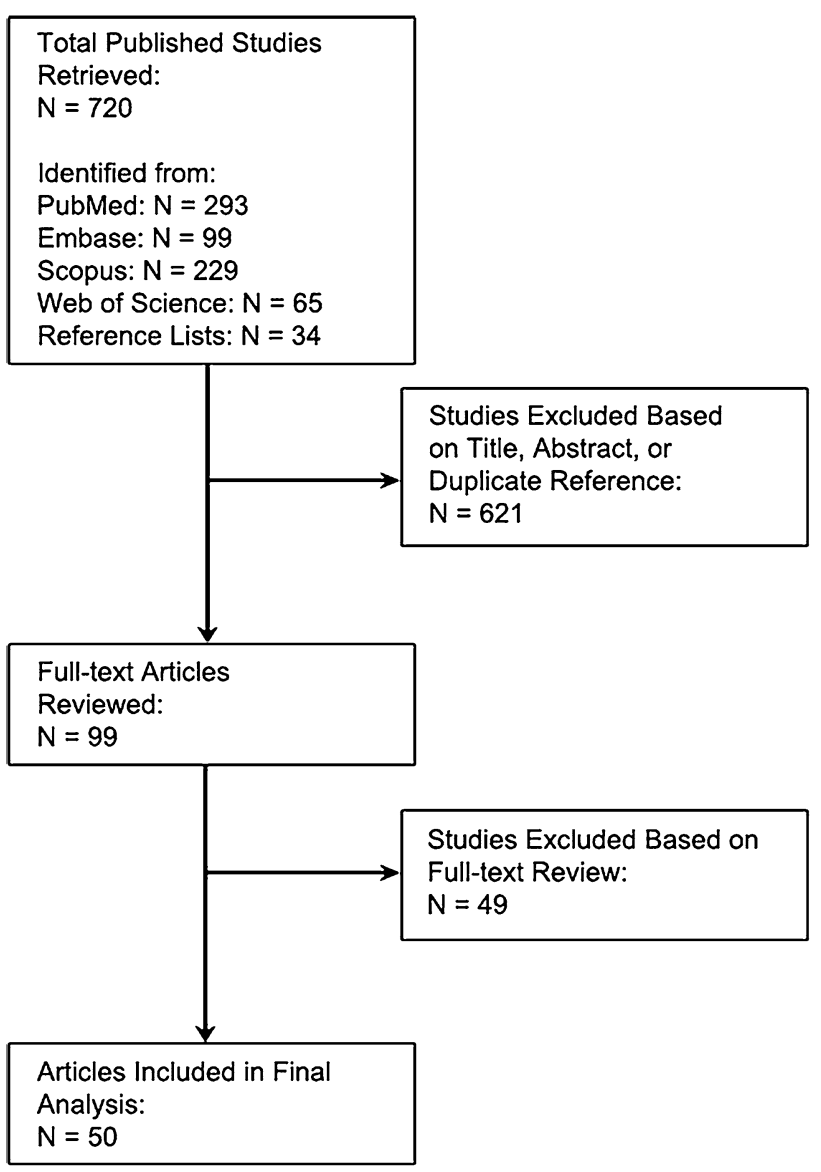

Fig. 1 Algorithm of the systematic review depicting results of the literature search and highlighting the number of articles identified and excluded at each point in the process.

none of the included investigations were specifically designed with the intent of evaluating the role of sex on the development of mortality or complications after spine surgery. All of the included investigations were graded as Level III quality because they were either retrospective case-control studies or works that performed post hoc comparisons evaluating heterogeneity of treatment effects.

Six investigations, representing 2,356,148 patients, were suited to pooling for the evaluation of mortality. For the six studies, the $\mathrm{Q}$ test identified significant heterogeneity $\left(\mathrm{p}<0.001\right.$ ) and the $\mathrm{I}^{2}$ was $90 \%$. As a result, a random-effects model was used. The Harbord test showed no statistically significant evidence of publication bias $(\mathrm{p}=0.4)$.

Fifty-two cohorts, representing 4,054,451 patients, were suited to pooling in the evaluation of complications. Cochrane $\mathrm{Q}$ testing indicated significant heterogeneity between studies $(\mathrm{p}<0.001)$ with an $\mathrm{I}^{2}$ of $94 \%$. The Harbord test demonstrated no significant evidence of publication bias $(\mathrm{p}=0.63)$. 
Subset analyses were conducted for studies dedicated to dysphagia after anterior cervical procedures and SSI because of reduced between-study heterogeneity for the works considering these specific complications. Four cohorts, representing 160,575 patients, regarding dysphagia after anterior cervical procedures were suitable for pooling as were six reporting on SSI (53,223 patients). The Harbord test indicated no evidence of publication bias for either of the specific complications considered $(\mathrm{p}=0.07$ for dysphagia and $p=0.94$ for SSI).

\section{Results}

Does Sex Influence the Odds of Mortality After Spine Surgery?

Ten studies were identified that considered sex-based differences in mortality (Appendix 2). Seven of 10 reported that females were at significantly decreased risk of mortality and three maintained no significant difference between the sexes. The pooled analysis indicated that males were at increased odds of mortality (OR, 1.63; 95\% CI, 1.35-1.97, $\mathrm{p}<0.001$; Fig. 2).
Does Sex Impact the Odds of Postoperative Complications After Spine Surgery?

Forty-five studies, with 64 distinct cohorts, were identified that considered sex-based differences in the development of one or more complications after spine surgery (Appendix 3). Females were identified as being at a decreased risk of complications in 25 cohorts, seven reported males to be at decreased risk, and 32 found no difference between the sexes. A random-effects model found no difference in the odds of postoperative complications based on patient sex (OR, 1.04; 95\% CI, 0.95-1.13, $\mathrm{p}=0.42$ ). The pooled analysis demonstrated no difference in the odds of dysphagia between the sexes (OR, 0.77; 95\% CI, 0.49-1.21, $\mathrm{p}=0.25$; Fig. 3 ) nor in terms of the odds of SSI (OR, 0.92; 95\% CI, 0.56-1.49, $\mathrm{p}=0.72$; Fig. 4).

\section{Discussion}

Biological sex has previously been found to influence outcomes after certain surgical interventions, including coronary artery bypass grafting and cardiothoracic procedures $[32,55,58]$. Less information is available with
Study
Journal
OR $(95 \% \mathrm{Cl})$
Weight

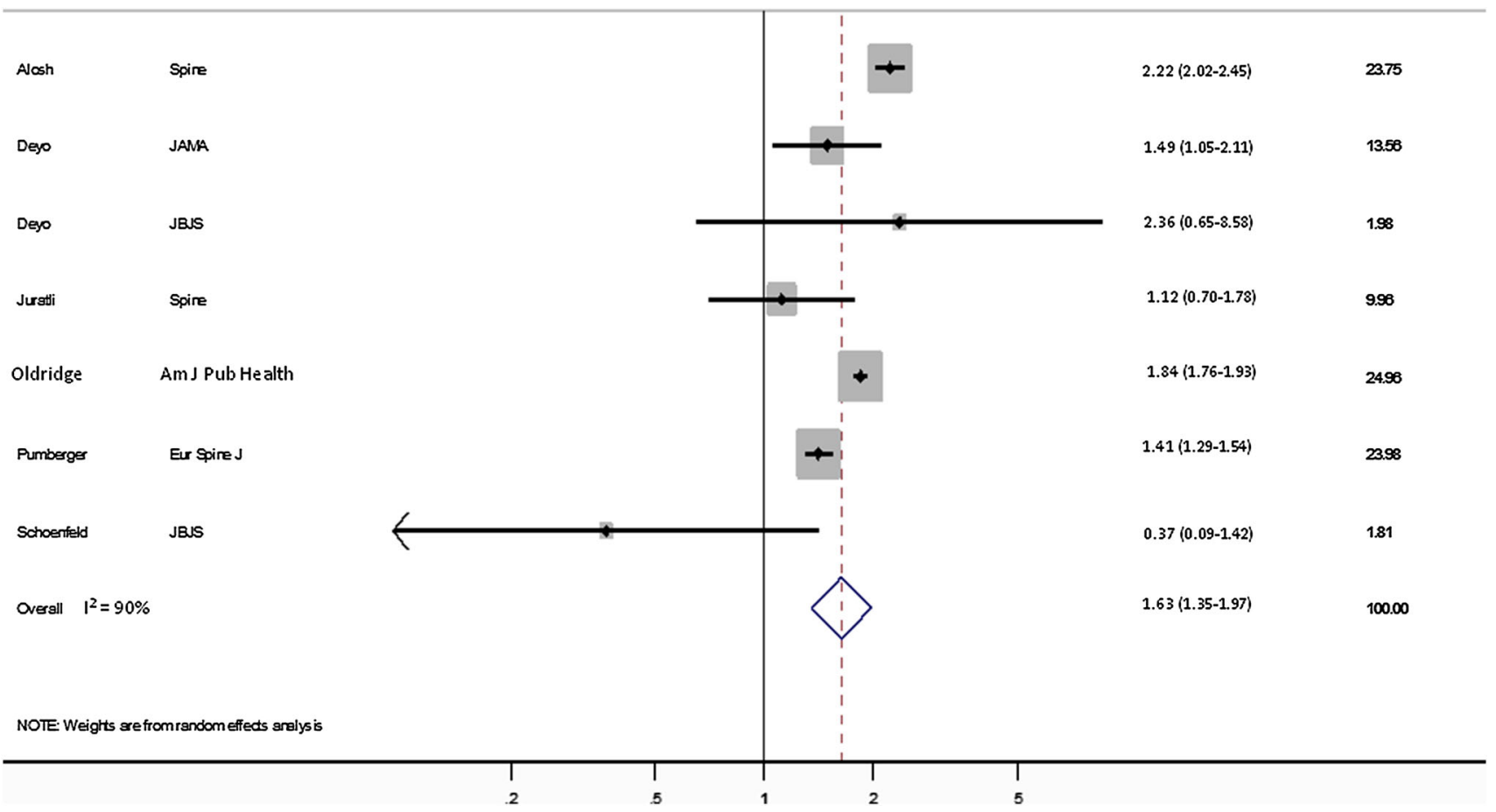

Fig. 2 Forest plot shows the ORs for mortality comparing males with females. 


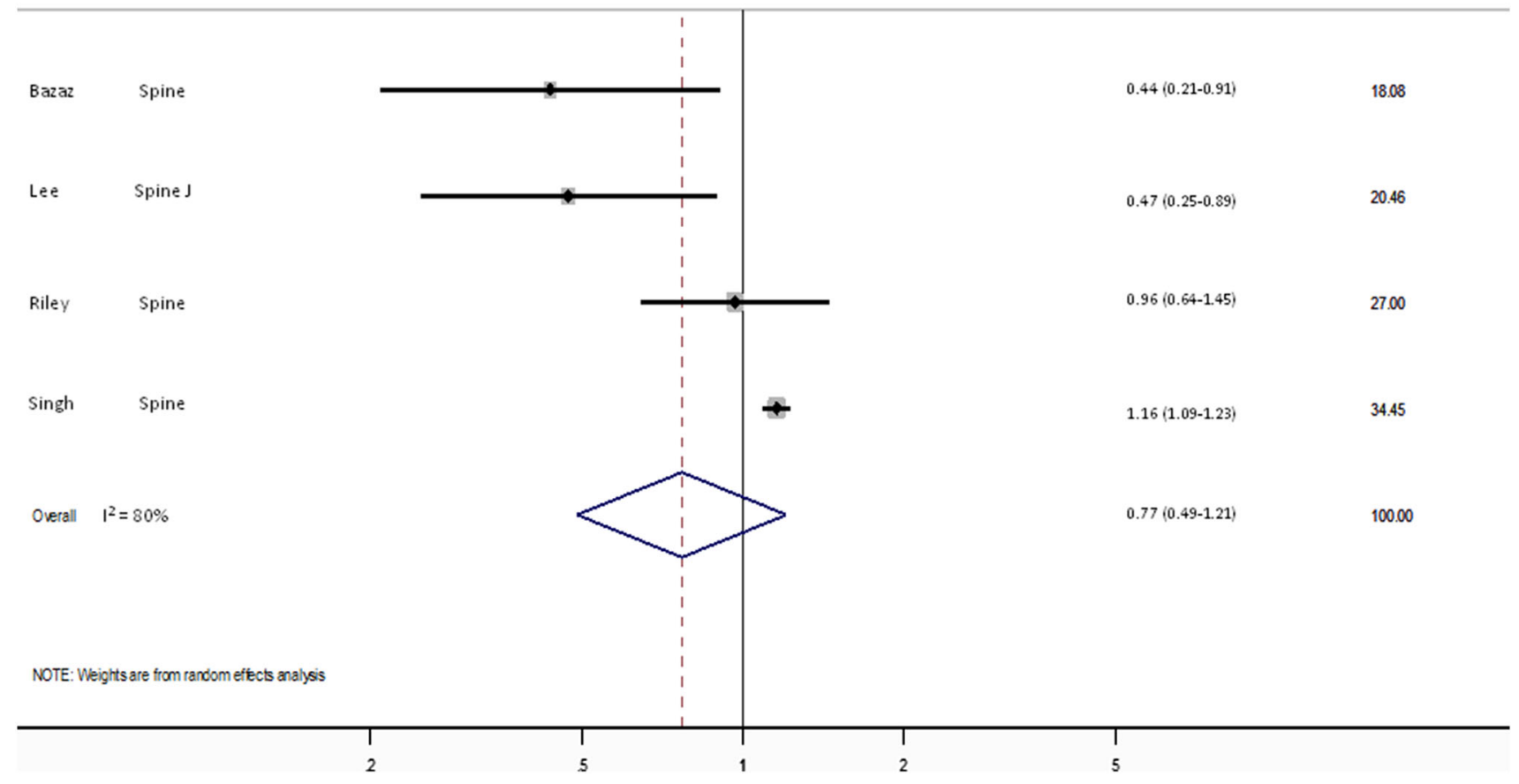

Fig. 3 Forest plot shows the ORs for dysphagia after anterior cervical spine procedures comparing males with females.

Study

Journal

Spine

Fang

Infect Con Hosp Epidemiol

Friedman

Hoffmann Spine

Honwitz J Neurosurg

Koutsoumbelis JBJS

Pull ter Gunne Spine

Overall $1^{2}=65 \%$

NOTE: Weights are from random effects analysis
OR $(95 \% \mathrm{Cl}) \quad$ Weight

\begin{tabular}{ll}
$1.58(0.74-3.36)$ & 17.19 \\
$0.66(0.30-1.42)$ & 16.80 \\
$0.44(0.17-1.09)$ & 14.33 \\
\hline $7.64(1.00-58.36)$ & 4.81 \\
$0.58(0.34-1.00)$ & 21.48 \\
\hline $1.18(0.83-1.67)$ & 25.39 \\
$0.92(0.56-1.49)$ & 100.00 \\
& \\
\hline
\end{tabular}

Fig. 4 Forest plot shows the ORs for SSI comparing males with females. 
regard to the role that sex may play in influencing postoperative morbidity and mortality after orthopaedic interventions and this is particularly striking for the specialty of spine surgery. Relatively few studies have even included patient sex as a covariate when considering risk factors for mortality and complications. Furthermore, among those efforts that have included patient sex as a predictor variable, substantially different conclusions have been reached. Statistical pooling of the results of individual studies could be used as a technique to increase power and potentially allow for more definitive determinations. In this context, we sought to perform a systematic review of the extant literature with the goal of evaluating whether biologic sex influences the odds of mortality or complications after the performance of spine surgery.

Our findings should not be accepted, however, without appreciating limitations associated with our analysis. The lack of spine surgical literature specifically addressing this topic is clearly the main limitation. None of the studies included in the systematic review were specifically designed with the intent of identifying sex-based differences in outcomes after spine surgery. Moreover, no prospective studies or controlled trials were identified and, to ensure uniformity, we did not include unpublished work or studies solely presented in conference proceedings. Marked heterogeneity between included studies, particularly with respect to methodology, surgical intervention, sample population, and the types of complications considered, is also a shortcoming. Although we attempted to address this using a conservative random-effects model that took into account the variation between studies, the inability to assume a uniform effect of patient sex across investigations was clearly a limiting factor. As a result, outside of dysphagia and SSI, which were considered in subset analyses, it is difficult to translate our findings regarding postsurgical complications. Finally, like with any systematic review, there is the possibility that reports addressing these topics were not captured by our search algorithm. We maintain that our rigorous approach to obtaining the pertinent literature, including a manual search of reference lists and queries of tables of contents, minimized the likelihood for this to have occurred, yet its potential impact on our findings cannot truly be quantified.

Nonetheless, our results indicated that males may be at elevated odds of mortality after spine surgery. The pooled OR estimate in the meta-analysis maintained a $63 \%$ increase in postoperative odds of death for males compared with females. This may be reflective of underlying physiologic differences between the sexes as well as variation in the number and severity of medical comorbidities [45, 46, $56,58]$. Females are known to have lower rates of coronary artery disease, peripheral vascular disease, and renal dysfunction [58]. They have also been hypothesized to tolerate shock to a greater extent and have a lower susceptibility to sepsis [55]. Seven studies in the systematic review independently identified males as having statistically elevated rates of mortality after spine surgery and similar results are apparent in other disciplines such as trauma surgery [56]. These facts, combined with the reduced between-study heterogeneity and absence of publication bias for the works included in our analysis, lend further support to our findings. Further research should be devoted to identifying the etiologies responsible for observed differences in mortality risk between the sexes as well as risk factors that may be modifiable in the perioperative period. Additionally, the findings of this systematic review should be confirmed in a scientifically rigorous, prospective analysis specifically designed to detect differences in mortality between male and female patients.

The clinical heterogeneity between studies considering postoperative morbidity substantially limits our capacity to draw firm conclusions. Although pooling failed to identify a statistically significant elevation in the odds of postsurgical complications, dysphagia, and SSI between sexes, the results could have been confounded by the sample populations, indications for surgery, and definitions of postoperative morbidity unique to the studies that were pooled. Given the deficiency of literature specifically intended to examine the effects of sex on postoperative morbidity and mortality after spine surgery, a large prospective study designed to identify sex-based differences in postoperative complications is clearly warranted. The ideal investigation would be multicentered in nature and sufficiently powered to address specific complications, including SSI, venous thromboembolic disease, reoperation, and 30-day readmission, rather than reporting results for an amalgam of nonspecific categories of perioperative morbidity (eg, one or more complications, major complications, and minor complications). Furthermore, such a study's capacity to prospectively determine sex-based differences in healthcare expenditures, environments of care, and functional outcomes in the mid- and long-term would invariably equate to best available evidence for the spine surgical field. Without question, the financial and logistic requirements for this kind of research would necessitate marshaling substantial resources within the spine surgical community, healthcare systems, insurance companies, and the US federal government.

Our results indicate that male patients may be at greater odds of mortality after spine surgery. Given that this determination was made using pooled data derived from multiple investigations, such information has value for the purposes of patient education, preoperative counseling, and prognosticating risk during the consent process. The quality of the studies included in the pooled analysis for postoperative complications causes us to interpret our 
determinations with extreme caution. Future research, of the kind outlined here, should be directed at determining the underlying factors responsible for increased mortality among male patients and prospective work specifically designed to evaluate sex-based differences in outcomes after spine surgery.

\section{References}

1. Alosh H, Riley LH 3rd, Skolasky RL. Insurance status, geography, race, and ethnicity as predictors of anterior cervical spine surgery rates and in-hospital mortality: an examination of United States trends from 1992 to 2005. Spine. 2009;34:1956-1962.

2. Bazaz R, Lee MJ, Yoo JU. Incidence of dysphagia after anterior cervical spine surgery: a prospective study. Spine. 2002;27:24532458.

3. Cahill KS, Chi JH, Day A, Claus EB. Prevalence, complications, and hospital charges associated with use of bone-morphogenetic proteins in spinal fusion procedures. JAMA. 2009;302:58-66.

4. Chen S, Anderson MV, Cheng WK, Wongworawat MD. Diabetes associated with increased surgical site infections in spinal arthrodesis. Clin Orthop Relat Res. 2009;467:1670-1673.

5. Cloyd JM, Acosta FL Jr, Cloyd C, Ames CP. Effects of age on perioperative complications of extensive multilevel thoracolumbar spinal fusion surgery. J Neurosurg Spine. 2010;12:402-408.

6. Danto J, DiCapua J, Nardi D, Pekmezaris R, Moise G, Lesser M, Dimarzio P. Multiple cervical levels: increased risk of dysphagia and dysphonia during anterior cervical discectomy. J Neurosurg Anesth. 2012;24:350-355.

7. Deyo RA, Cherkin DC, Loeser JD, Bigos SJ, Ciol MA. Morbidity and mortality in association with operations on the lumbar spine. The influence of age, diagnosis, and procedure. J Bone Joint Surg Am. 1992;74:536-543.

8. Deyo RA, Mirza SK, Martin BI, Kreuter W, Goodman DC, Jarvik JG. Trends, major medical complications, and charges associated with surgery for lumbar spinal stenosis in older adults. JAMA. 2010;303:1259-1265.

9. Fang A, Hu SS, Endres N, Bradford DS. Risk factors for infection after spinal surgery. Spine. 2005;30:1460-1465.

10. Fineberg SJ, Ahmadinia K, Patel AA, Oglesby M, Singh K. Incidence and mortality of cardiac events in lumbar spine surgery. Spine. 2013;38:1422-1429.

11. Fineberg SJ, Kurd MF, Patel AA, Singh K. Incidence and risk factors for gastrointestinal hemorrhage after lumbar fusion. Spine. 2013;38:1584-1589.

12. Fineberg SJ, Nandyala SV, Kurd MF, Marquez-Lara A, Noureldin M, Sankaranarayanan S, Patel AA, Oglesby M, Singh K. Incidence and risk factors for postoperative ileus following anterior, posterior, and circumferential lumbar fusion. Spine J. 2014; 14:1680-1685.

13. Fineberg SJ, Nandyala SV, Marquez-Lara A, Oglesby M, Patel AA, Singh K. Incidence and risk factors for postoperative delirium after lumbar spine surgery. Spine. 2013;38:1790-1796.

14. Fineberg SJ, Oglesby M, Patel AA, Pelton MA, Singh K. The incidence and mortality of thromboembolic events in lumbar spine surgery. Spine. 2013;38:1154-1159.

15. Fineberg SJ, Oglesby M, Patel AA, Singh K. Incidence and mortality of perioperative cardiac events in cervical spine surgery. Spine. 2013;38:1268-1274.

16. Fineberg SJ, Oglesby M, Patel AA, Singh K. Incidence, risk factors, and mortality associated with aspiration in cervical spine surgery. Spine. 2013;38:E1189-1195.
17. Friedman ND, Sexton DJ, Connelly SM, Kaye KS. Risk factors for surgical site infection complicating laminectomy. Infect Cont Hosp Epidemiol. 2007;28:1060-1065.

18. Garg J, Woo K, Hirsch J, Bruffey JD, Dilley RB. Vascular complications of exposure for anterior lumbar interbody fusion. $J$ Vasc Surg. 2010;51:946-950; discussion 950.

19. Goz V, McCarthy I, Weinreb JH, Dallas K, Bendo JA, Lafage V, Errico TJ. Venous thromboembolic events after spinal fusion: which patients are at high risk? J Bone Joint Surg Am. 2014;96: 936-942.

20. Goz V, Weinreb JH, McCarthy I, Schwab F, Lafage V, Errico TJ. Perioperative complications and mortality after spinal fusions: analysis of trends and risk factors. Spine. 2013;38:1970-1976.

21. Gruskay JA, Fu M, Basques B, Bohl DD, Buerba R, Webb ML, Grauer JN. Factors affecting length of stay and complications following elective anterior cervical discectomy and fusion: a study of 2164 patients from the American College of Surgeons National Surgical Quality Improvement Project Database (ACS NSQIP). $J$ Spinal Disord Tech. 2014 Feb 12 [Epub ahead of print].

22. Hoffmann MF, Jones CB, Sietsema DL. Complications of rhBMP-2 utilization for posterolateral lumbar fusions requiring reoperation: a single practice, retrospective case series report. Spine J. 2013;13:1244-1252.

23. Horwitz NH, Curtin JA. Prophylactic antibiotics and wound infections following laminectomy for lumber disc herniation. $J$ Neurosurg. 1975;43:727-731.

24. Javalkar V, Cardenas R, Tawfik TA, Khan IR, Bollam P, Banerjee AD, Nanda A. Reoperations after surgery for lumbar spinal stenosis. World Neurosurg. 2011;75:737-742.

25. Juratli SM, Mirza SK, Fulton-Kehoe D, Wickizer TM, Franklin GM. Mortality after lumbar fusion surgery. Spine. 2009;34:740747.

26. King JT Jr, Abbed KM, Gould GC, Benzel EC, Ghogawala Z. Cervical spine reoperation rates and hospital resource utilization after initial surgery for degenerative cervical spine disease in 12,338 patients in Washington State. Neurosurgery. 2009;65: 1011-1022.

27. Koutsoumbelis S, Hughes AP, Girardi FP, Cammisa FP Jr, Finerty EA, Nguyen JT, Gausden E, Sama AA. Risk factors for postoperative infection following posterior lumbar instrumented arthrodesis. J Bone Joint Surg Am. 2011;93:1627-1633.

28. Kurtz SM, Lau E, Ong KL, Carreon L, Watson H, Albert T, Glassman S. Infection risk for primary and revision instrumented lumbar spine fusion in the Medicare population. J Neurosurg Spine. 2012;17:342-347.

29. Lee MJ, Bazaz R, Furey CG, Yoo J. Risk factors for dysphagia after anterior cervical spine surgery: a two-year prospective cohort study. Spine J. 2007;7:141-147.

30. Lee MJ, Konodi MA, Cizik AM, Bransford RJ, Bellabarba C, Chapman JR. Risk factors for medical complication after spine surgery: a multivariate analysis of 1,591 patients. Spine J. 2012;12: 197-206.

31. Lykissas MG, Aichmair A, Hughes AP, Sama AA, Lebl DR, Taher F, Du JY, Cammisa FP, Girardi FP. Nerve injury after lateral lumbar interbody fusion: a review of 919 treated levels with identification of risk factors. Spine J. 2014;14:749-758.

32. MacDonald SJ, Charron KD, Bourne RB, Naudie DD, McCalden RW, Rorabeck CH. The John Insall Award: gender-specific total knee replacement: prospectively collected clinical outcomes. Clin Orthop Relat Res. 2008;466:2612-2616.

33. Marquez-Lara A, Nandyala SV, Fineberg SJ, Singh K. Cerebral vascular accidents after lumbar spine fusion. Spine. 2014;39:673677.

34. Moher D, Liberati A, Tetzlaff J, Altman DG; PRISMA Group. Preferred reporting items for systematic reviews and 
meta-analyses: the PRISMA statement. Ann Intern Med. 2009;151:264-269.

35. Nandyala SV, Marquez-Lara A, Fineberg SJ, Singh R, Singh K. Incidence and risk factors for perioperative visual loss after spinal fusion. Spine J. 2014;14:1694-1701.

36. Nassr A, Eck JC, Ponnappan RK, Zanoun RR, Donaldson WF 3rd, Kang JD. The incidence of C5 palsy after multilevel cervical decompression procedures: a review of 750 consecutive cases. Spine. 2012;37:174-178.

37. Oglesby M, Fineberg SJ, Patel AA, Pelton MA, Singh K. The incidence and mortality of thromboembolic events in cervical spine surgery. Spine. 2013;38:E521-527.

38. Oldridge NB, Yuan Z, Stoll JE, Rimm AR. Lumbar spine surgery and mortality among Medicare beneficiaries, 1986. Am J Public Health. 1994;84:1292-1298.

39. Pugely AJ, Martin CT, Gao Y, Mendoza-Lattes S. Causes and risk factors for 30-day unplanned readmissions after lumbar spine surgery. Spine. 2014;39:761-768.

40. Pull ter Gunne AF, Cohen DB. Incidence, prevalence, and analysis of risk factors for surgical site infection following adult spinal surgery. Spine. 2009;34:1422-1428.

41. Pumberger M, Chiu YL, Ma Y, Girardi FP, Vougioukas V, Memtsoudis SG. Perioperative mortality after lumbar spinal fusion surgery: an analysis of epidemiology and risk factors. Eur Spine J. 2012;21:1633-1639.

42. Riley LH 3rd, Skolasky RL, Albert TJ, Vaccaro AR, Heller JG. Dysphagia after anterior cervical decompression and fusion: prevalence and risk factors from a longitudinal cohort study. Spine. 2005;30:2564-2569.

43. Scheer JK, Tang JA, Smith JS, Klineberg E, Hart RA, Mundis GM Jr, Burton DC, Hostin R, O'Brien MF, Bess S, Kebaish KM, Deviren V, Lafage V, Schwab F, Shaffrey CI, Ames CP, International Spine Study Group. Reoperation rates and impact on outcome in a large, prospective, multicenter, adult spinal deformity database: clinical article. J Neurosurg Spine. 2013;19:464470.

44. Schnee CL, Freese A, Weil RJ, Marcotte PJ. Analysis of harvest morbidity and radiographic outcome using autograft for anterior cervical fusion. Spine. 1997;22:2222-2227.

45. Schoenfeld AJ, Bader JO. Cauda equina syndrome: an analysis of incidence rates and risk factors among a closed North American military population. Clin Neurol Neurosurg. 2012;114:947-950.

46. Schoenfeld AJ, Carey PA, Cleveland AW 3rd, Bader JO, Bono CM. Patient factors, comorbidities, and surgical characteristics that increase mortality and complication risk after spinal arthrodesis: a prognostic study based on 5,887 patients. Spine J. 2013;13: 1171-1179.

47. Schoenfeld AJ, Herzog JP, Dunn JC, Bader JO, Belmont PJ Jr. Patient-based and surgical characteristics associated with the acute development of deep venous thrombosis and pulmonary embolism after spine surgery. Spine. 2013;38:1892-1898.
48. Schoenfeld AJ, Laughlin M, Bader JO, Bono CM. Characterization of the incidence and risk factors for the development of lumbar radiculopathy. J Spinal Disord Tech. 2012;25:163-167.

49. Schoenfeld AJ, Nelson JH, Burks R, Belmont PJ Jr. Incidence and risk factors for lumbar degenerative disc disease in the United States military: 1999-2008. Mil Med. 2011;176:1320-1324.

50. Schoenfeld AJ, Ochoa LM, Bader JO, Belmont PJ Jr. Risk factors for immediate postoperative complications and mortality following spine surgery: a study of 3475 patients from the National Surgical Quality Improvement Program. J Bone Joint Surg Am. 2011;93:1577-1582.

51. Schwab FJ, Hawkinson N, Lafage V, Smith JS, Hart R, Mundis G, Burton DC, Line B, Akbarnia B, Boachie-Adjei O, Hostin R, Shaffrey CI, Arlet V, Wood K, Gupta M, Bess S, Mummaneni PV, International Spine Study Group. Risk factors for major perioperative complications in adult spinal deformity surgery: a multi-center review of 953 consecutive patients. Eur Spine J. 2012;21:2603-2610.

52. Shen Y, Silverstein JC, Roth S. In-hospital complications and mortality after elective spinal fusion surgery in the United States: a study of the Nationwide Inpatient Sample from 2001 to 2005. $J$ Neurosurg Anesthiol. 2009;21:21-30.

53. Singh K, Marquez-Lara A, Nandyala SV, Patel AA, Fineberg SJ. Incidence and risk factors for dysphagia after anterior cervical fusion. Spine. 2013;38:1820-1825.

54. Sterne JAC. Updated tests for small-study effects in meta-analyses. In: Sterne JAC, ed. Meta-analysis in STATA. College Station, TX, USA: STATA Corp; 2009:138-150.

55. Taylor BA, Casas-Ganem J, Vaccaro AR, Hilibrand AS, Hanscom BS, Albert TJ. Differences in the work-up and treatment of conditions associated with low back pain by patient gender and ethnic background. Spine. 2005;30:359-364.

56. Trentzsch H, Lefering R, Nienaber U, Kraft R, Faist E, Piltz S. The role of biological sex in severely traumatized patients on outcomes: a matched-pair analysis. Ann Surg. 2014 Jul 15 [Epub ahead of print].

57. Wang MC, Shivakoti M, Sparapani RA, Guo C, Laud PW, Nattinger AB. Thirty-day readmissions after elective spine surgery for degenerative conditions among US Medicare beneficiaries. Spine J. 2012;12:902-911.

58. Williams M, Kodali SK, Hahn RT, Humphries KH, Nkomo VT, Cohen DJ, Douglas PS, Mack M, McAndrew TC, Svensson L, Thourani VH, Tuzcu EM, Weissman NJ, Kirtane AJ, Leon MB. Sex-related differences in outcomes after transcatheter or surgical aortic valve replacement in patients with severe aortic stenosis: Insights from the PARTNER Trial (Placement of Aortic Transcatheter Valve). J Am Coll Cardiol. 2014;63:1522-1528.

59. Zheng F, Cammisa FP Jr, Sandhu HS, Girardi FP, Khan SN. Factors predicting hospital stay, operative time, blood loss, and transfusion in patients undergoing revision posterior lumbar spine decompression, fusion, and segmental instrumentation. Spine. 2002;27:818-824. 